\title{
Advanced oxidation of photographic processing effluents on novel heterogeneous fibrous catalyst
}

\author{
V. V. Ishtchenko, K. D. Huddersman \& Z. Yang \\ Faculty of Health \& Life Sciences, De Montfort University, UK
}

\begin{abstract}
A novel heterogeneous catalyst, based on Fenton's chemistry, was evaluated for the treatment of KODAK Silver Bearing (SB) photographic processing effluents with high Chemical Oxygen Demand (COD) value. The effect of temperature, the nature and concentration of the oxidant (air and/or hydrogen peroxide), the duration of catalytic treatment and the dilution factor of the effluent on the reduction in COD were investigated. The catalyst and bubbled air (with no hydrogen peroxide present) resulted in a significant COD reduction of the effluent of $56 \%$ after 18 hours of treatment at room temperature. It was found that most of the COD reduction occurred within the first four hours of treatment. Using air on its own, as oxidant was found to be sufficient, with only a slight improvement on the addition of hydrogen peroxide. Ambient temperature was preferred for the catalytic treatment of the effluent, as an increase in temperature up to $60^{\circ} \mathrm{C}$ led to less $\mathrm{COD}$ reduction which may arise from a change in the redox potential of the active transition metal $\left(\mathrm{Fe}^{3+}\right)$ complex or to the formation of recalcitrant products.
\end{abstract}

Keywords: Advanced oxidation, photographic processing effluents, heterogeneous catalyst, Fenton's chemistry.

\section{Introduction}

The treatment of wastewater is one of the most important subjects in the area of pollution control. In the monitoring and control of wastewaters, including trade complex effluents, such as photographic processing effluents (PPE), chemical oxygen demand (COD) is used as a measure of the extent of pollution as it is the 
oxygen required to oxidise organic compounds to $\mathrm{CO}_{2}$ and $\mathrm{H}_{2} \mathrm{O}$ by a strong chemical oxidant. A number of organic and inorganic pollutants found in PPE, such as ammonium salts, ferrocyanide, thiocyanate, organic acids, aminophenols and phenylenediamines, are of special interest in waste treatment. Photographic processing effluents as water pollutants were of concern in the early 1970s, and ever since then, numerous studies have been undertaken in the treatment of PPE $[1,2]$. A number of methods have been investigated in order to treat PPE, such as reduction in COD by oxidation [2-5], UV radiation [6, 7], biological treatment $[8,9]$, incineration $[10]$ and a combination of oxidation and UV radiation [11], with most of the published work in the patent literature. Since photographic processing effluents have very high oxygen demand (COD value $90,000-150,000 \mathrm{mg} \mathrm{O}_{2} / \mathrm{L}$ ), the use of chemical oxidation to reduce this is very attractive, particularly, the use of hydrogen peroxide as it is an ecologically friendly and pure product. Fenton's reagent $\left(\mathrm{H}_{2} \mathrm{O}_{2}-\mathrm{Fe}^{2+}\right)$ is extensively used in oxidation of photographic processing effluent $[2,3,12]$ though other oxidative treatments, involving $\mathrm{H}_{2} \mathrm{O}_{2}$ alone [13], $\mathrm{H}_{2} \mathrm{O}_{2}$ and $\mathrm{Fe}$ powder (which is based on the homogeneous Fenton's reagent by dissolution of iron) [14], $\mathrm{ClO}^{-}$[15], and $\mathrm{O}_{3}[11]$ are also used.

In the present study we evaluated the activity of a novel heterogeneous fibrous catalyst [16], based on Fenton's chemistry towards oxidation of silverbearing (SB) photographic processing effluents from KODAK. The ability of the catalyst to decompose the effluent was measured as the reduction in COD value with respect to that of the initial feed. The effect of temperature, nature and concentration of the oxidant and the duration of catalytic treatment on the reduction in COD value were investigated.

\section{Experimental section}

\subsection{Reagents}

The following reagents were used in present study: Mercury Sulphate (Aldrich), Sulphuric Acid (98\%, Aldrich), Potassium Dichromate (Aldrich), Hydrogen Peroxide (27.5\%, Aldrich), Potassium Hydrogen Phthalate (KHP). All chemicals were of analytical grade.

$\mathrm{SB}_{1}$ and $\mathrm{SB}_{2}$ effluents used in this study have an initial $\mathrm{COD}$ value around 80,000 and $40,000 \mathrm{mg} / \mathrm{L}$, respectively. $\mathrm{SB}_{1}$ and $\mathrm{SB}_{2}$ effluents were from different batches of photo-processing effluent collected at different times and delivered to our laboratory by KODAK Ltd. These effluents mainly contained triethanolamine (up to $20 \%$ ), acetic acid (up to $43 \%$ ), ammonium bromide (up to $77 \%$ ), ammonium ferric ethylenediaminetetraacetic (up to $25 \%$ ), ammonium thiocyanate (up to 25\%), ammonium thiosulphate (up to 60\%), ammonium nitrate (up to $10 \%$ ), ammonium sulphite (up to $10 \%$ ), ferric ammonium propylenediaminetetraacetic (up to $20 \%$ ), hexamethylenetetramine (up to $30 \%$ ), organic silicone (15\%), sodium bisulphite (up to $30 \%$ ), sodium bisulphite (up to $10 \%$ ) and silver thiosulfate complex (up to $5 \mathrm{mg} / \mathrm{L}$ ). 


\subsection{Analysis}

COD determination is based on the theoretical amount of oxygen required to oxidize organic compounds to $\mathrm{CO}_{2}$ and $\mathrm{H}_{2} \mathrm{O}$. The most commonly used standard chemical is potassium hydrogen phthalate (KHP) [17]. The theoretical oxygen demand of KHP is expressed by Equation (1)

$$
\mathrm{KC}_{8} \mathrm{H}_{5} \mathrm{O}_{4}+7.5 \mathrm{O}_{2} \rightarrow 8 \mathrm{CO}_{2}+2 \mathrm{H}_{2} \mathrm{O}+\mathrm{KOH}
$$

According to the equation, the theoretical oxygen demand for KHP is $1.175 \mathrm{mg}$ $\mathrm{O}_{2}$ per mg KHP.

In the present study a stock standard solution of $1202 \mathrm{mg} / \mathrm{L} \mathrm{KHP} \mathrm{which} \mathrm{was}$ equivalent to $2000 \mathrm{mg} / \mathrm{L}$ COD was prepared. The KHP concentration series equivalent to $2000,1000,750,300$ and $150 \mathrm{mg} / \mathrm{L}$ COD for calibration curve construction were prepared from the stock KHP standard solution. For each COD test $0.05 \mathrm{~g}$ of mercury sulphate was put in a test tube, followed by the addition of $2.50 \mathrm{ml}$ concentrated sulphuric acid, and $0.5 \mathrm{ml} 1 \mathrm{~N}(0.167 \mathrm{M})$ potassium dichromate. $2 \mathrm{ml}$ KHP standard solution of each concentration was then added to the test tubes with COD reagent. The blank was prepared the same way except that $2 \mathrm{ml}$ sample was replaced by $2 \mathrm{ml}$ double distilled water. After thoroughly shaking to mix the solutions, the test tubes were put in the COD reactor $(\mathrm{HACH}, \mathrm{Camlab})$ that was preheated up to $150{ }^{\circ} \mathrm{C}$ in advance of test tube insertion. The test tubes were left in the reactor for 2 hours. Absorbance of the standard was determined at $620 \mathrm{~nm}$ using UV/VIS Spectrophotometer (UNICAM UV2-100) after the samples had cooled to room temperature. Calibration graph was plotted of absorbance against COD value for the standard series. All standards were performed in triplicate and results averaged.

The COD determination process for the samples was the same as for the standard curve construction except that $2 \mathrm{ml} \mathrm{KHP}$ was replaced by $2 \mathrm{ml}$ sample.

\subsection{Catalytic oxidation of SB effluent under static conditions}

The experimental set up for catalytic oxidation of KODAK SB photographic processing effluent under static conditions consisted of a $100 \mathrm{ml}$ three-necked round flask (reactor) operated in batch mode, condenser, thermometer, magnetic stirrer, compressor and rotameter for air supply and control. Initial feed from KODAK $\mathrm{SB}_{1}$ effluent was diluted 100 times before catalysis followed by filtration of the diluted solution to remove suspended solids. For KODAK $\mathrm{SB}_{2}$ effluent, the dilution factors were either 15 or 50 .

Fibrous catalyst was placed into the reactor containing $50 \mathrm{ml}$ of the filtered solution. Preparation procedure of the catalyst, containing $\mathrm{Fe}^{3+}$ cations is described in our previous papers $[16,18]$. Hydrogen peroxide of a known concentration was added into this solution before catalysis. Air was delivered to the solution from compressor through the rotameter at a rate of $0.154 \mathrm{~m}^{3} / \mathrm{h}$. The magnetic stirrer was used only when $\mathrm{H}_{2} \mathrm{O}_{2}$ (without bubbled air) was the oxidant for catalysis. Experiments were carried out at temperatures of $25{ }^{\circ} \mathrm{C}, 40{ }^{\circ} \mathrm{C}$ and $60{ }^{\circ} \mathrm{C}$. The amount of hydrogen peroxide was varied from 10 up to $200 \mathrm{mg} / \mathrm{L}$. 
Experiments investigating the effect of duration of catalysis, which was $0.5,1,2$, 3,4 and 18 hours, were individually set up. Samples of reaction medium of $2 \mathrm{ml}$ were withdrawn for COD analysis after completing the catalysis. Feed without catalyst but in the presence of oxidants (air and/or hydrogen peroxide) and under the same experimental conditions was used as a reference sample in each experiment. The procedures were repeated twice per each sample. Concentration of $\mathrm{Fe}^{3+}$ on the catalyst was determined through inductive coupled plasma (ICP) technique and expressed as amount of $\mathrm{Fe}^{3+}(\mathrm{mmol})$ per gram of fibre [16].

\section{Results and discussion}

\subsection{Effect of duration of catalysis}

As can be seen from Figure 1, the maximum rate of COD reduction in the presence of catalyst and bubbled air occurred within the first 30 minutes of catalysis followed by a further slow decrease in COD value up to 18 hours of treatment. $44 \%$ and $56 \%$ COD reduction was achieved after 4 and 18 hours of catalytic oxidation, respectively. Photographic processing effluents contain oxidisable inorganic substances, such as $\mathrm{SO}_{3}{ }^{2-}, \mathrm{S}_{2} \mathrm{O}_{3}{ }^{2-}, \mathrm{NH}_{3}$, which may contribute to the COD reduction. Inorganic sulphur-oxo compounds can easily be oxidised using air or hydrogen peroxide to $\mathrm{SO}_{4}{ }^{2-}$. However, there was no significant decrease in the COD value of the original feed after oxidation with bubbled air with no catalyst present (control sample) suggesting that the feed contained little easily oxidisable sulphur compounds. COD reduction values were calculated with respect to those of the control sample of the feed.

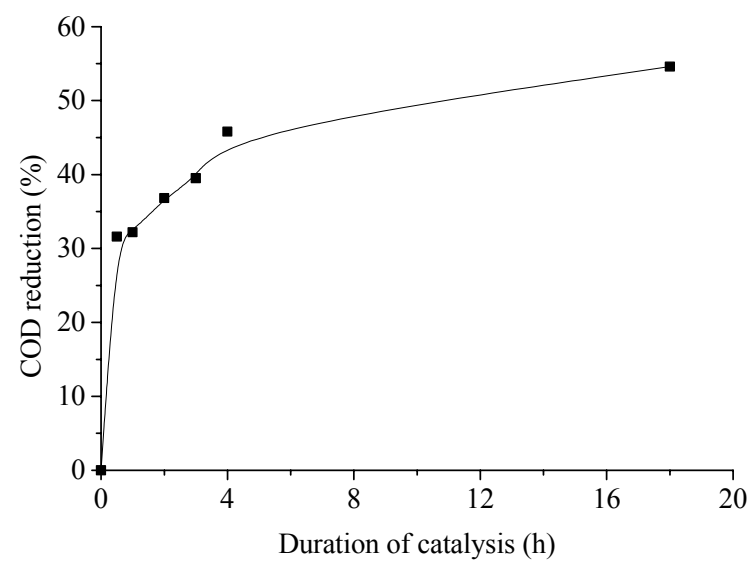

Figure 1: $\quad$ COD reduction of $\mathrm{KODAK} \mathrm{SB}_{1}$ effluent as a function of time in the catalytic oxidation using $\mathrm{Fe}^{3+}$ fibrous catalyst and bubbled air at room temperature. 


\subsection{Effect of temperature}

As shown in Table 1, increase in temperature from $25^{\circ} \mathrm{C}$ to $40^{\circ} \mathrm{C}$ does not result in significant COD reduction, with $34.6 \%$ and $36.5 \%$ COD reduction, respectively, after 4 hours of catalytic oxidation. However, increasing the temperature up to $60^{\circ} \mathrm{C}$ resulted in just $10.8 \%$ of $\mathrm{COD}$ reduction. This phenomenon could be explained by the formation of more complex substances during the high-temperature catalytic oxidation (dimeric compounds, for example), which is an object of our future research. However, we do not exclude, that the temperature effect may arise from a change in the redox potential of the active transition metal $\left(\mathrm{Fe}^{3+}\right)$ complex on the catalyst, as the structure and nature of the complex and hence the resultant redox state of the active metal site could be temperature dependent. All these effects would influence the ability of the catalyst to switch between $\mathrm{Fe}^{3+} / \mathrm{Fe}^{2+}$ redox states and hence affect its catalytic activity $[19,20]$. It is unlikely to arise from $\mathrm{Fe}^{3+}$ leaching into solution from the catalyst, as has been described in detail in our earlier publications $[16,18]$. The COD of the initial feed after oxidation with bubbled air but with no catalyst was found to be little different from that of the original feed. Based on the results, room temperature is the optimal temperature for catalytic treatment and all the following work was therefore conducted at room temperature.

Table 1: COD reduction on oxidation of KODAK $\mathrm{SB}_{1}$ effluent using $\mathrm{Fe}^{3+}$ fibrous catalyst and bubbled air as a function of temperature.

\begin{tabular}{|c|c|c|c|c|c|}
\hline Sample & $\begin{array}{c}\text { Temperature } \\
\left({ }^{0} \mathrm{C}\right)\end{array}$ & $\begin{array}{c}\text { Duration of } \\
\text { catalysis } \\
\text { (hour) }\end{array}$ & $\begin{array}{c}\mathrm{COD}_{\text {ref }} \\
(\mathrm{mg} / \mathrm{L})\end{array}$ & $\begin{array}{c}\mathrm{COD}_{\text {cat }} \text { / } \\
\mathrm{COD}_{\text {ref }}\end{array}$ & $\begin{array}{c}\mathrm{COD} \\
\text { reduction } \\
(\%)\end{array}$ \\
\hline Initial feed & 25 & 0 & 840.0 & 1 & \\
\hline 1 & 25 & 4 & 839.8 & 0.654 & 34.6 \\
\hline 2 & 40 & 4 & 839.4 & 0.635 & 36.5 \\
\hline 3 & 60 & 4 & 839.8 & 0.892 & 10.8 \\
\hline
\end{tabular}

\subsection{Effect of concentration of $\mathrm{H}_{2} \mathrm{O}_{2}$}

From the results shown in Figure 2, maximum reduction of COD of $25-26 \%$ after 30 minutes catalytic treatment was achieved for concentrations of hydrogen peroxide of 10 and $50 \mathrm{mg} / \mathrm{l}$, respectively. Higher concentrations of $\mathrm{H}_{2} \mathrm{O}_{2}$ of 100 and $200 \mathrm{mg} / \mathrm{L}$ are shown to result in less reduction of just 10-6\% (Fig. 2), which indicates an excess of residual $\mathrm{H}_{2} \mathrm{O}_{2}$. According to Talinli and Anderson [21], 
COD measured in the sample taken after catalysis must be calculated according to equation(2) to yield a corrected value. For the ranges of residual $\mathrm{H}_{2} \mathrm{O}_{2}$ from 20 to $1000 \mathrm{mg} / \mathrm{L}$, the percent of COD removal $(\eta)$ is then determined through equation (3).

$$
\mathrm{S}_{\mathrm{E}}=\mathrm{COD}_{\mathrm{t}}-\mathrm{R}_{\mathrm{p}} \times 0.25
$$

where $\mathrm{S}_{\mathrm{E}}$ is the corrected value of $\mathrm{COD}$ after the reaction, $\mathrm{COD}_{\mathrm{t}}$ is the 'reading' value of $C O D$ after the reaction, $R_{p}$ is the residual amount of $\mathrm{H}_{2} \mathrm{O}_{2}$ left in solution after the reaction.

$$
\eta=\left[\left(S_{0}-S_{E}\right) / S_{0}\right] \times 100
$$

where $\mathrm{S}_{0}$ is the initial value of COD of the feed.

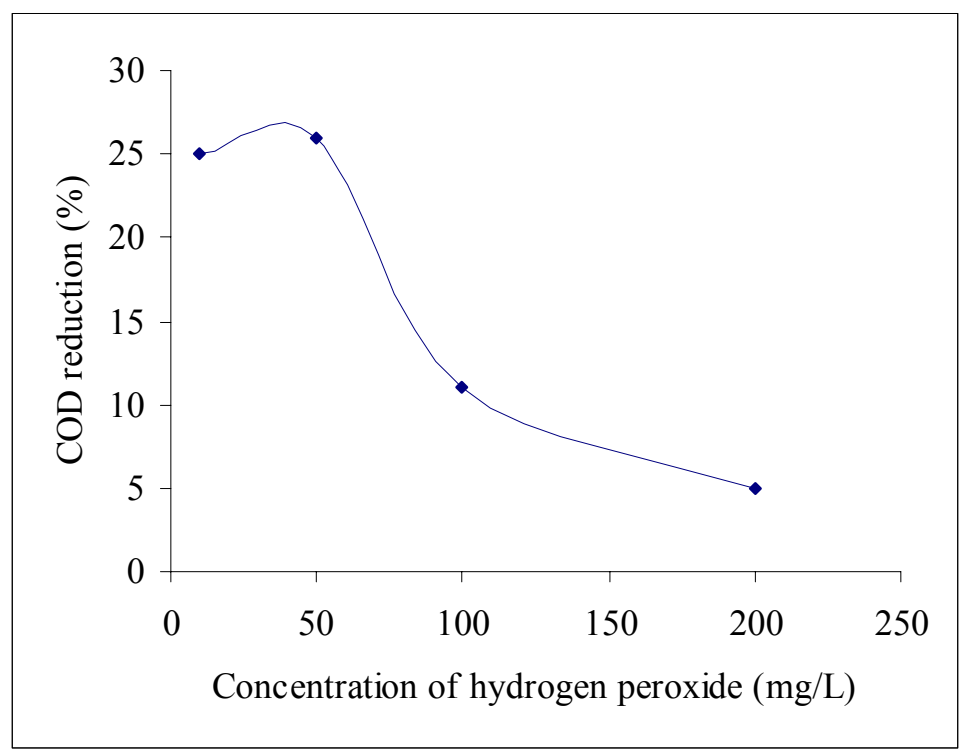

Figure 2: $\quad \mathrm{COD}$ reduction of KODAK $\mathrm{SB}_{1}$ effluent as a function of $\mathrm{H}_{2} \mathrm{O}_{2}$ concentration in the catalytic oxidation using $\mathrm{Fe}^{3+}$ fibrous catalyst at room temperature.

Using $50 \mathrm{mg} / \mathrm{L}$ of $\mathrm{H}_{2} \mathrm{O}_{2}$ for the catalysis and assuming that none of the hydrogen peroxide was consumed during the reaction, the difference between observed COD reduction (26\%) and COD reduction corrected for hydrogen peroxide in accord with formulas 2 and $3(27.5 \%)$ gives $1.5 \%$ maximum relative error, which is very minor. With $200 \mathrm{mg} / \mathrm{L}$ of hydrogen peroxide and again assuming that none of the $\mathrm{H}_{2} \mathrm{O}_{2}$ was consumed during the reaction the maximum relative error would now be $11.95 \%$, which is more significant. The degree of COD reduction may also depend on the type and concentration of pollutants in 
wastewater with the most advantageous results of reduction in COD at lower hydrogen peroxide concentration [22]. Thus, the effective amount of hydrogen peroxide of $50 \mathrm{mg} / \mathrm{l}$ for $\mathrm{SB}_{1}$ effluent was selected for further research studies as the optimum amount in terms of COD reduction. Additionally, one of the main targets of this study was to test whether air rather than hydrogen peroxide could be used for the catalytic oxidation. This would reduce cost and allow the use of less than a stoichiometric amount of $\mathrm{H}_{2} \mathrm{O}_{2}$.

\subsection{Effect of the nature of oxidant}

According to Figure 3 there is little difference in COD reduction between the three oxidant systems air, $\mathrm{H}_{2} \mathrm{O}_{2}$ and air $+\mathrm{H}_{2} \mathrm{O}_{2}$ after 4 hours of treatment. Catalytic oxidation of the feed in the presence of both air and hydrogen peroxide seems to be slightly more promising. It can be concluded that using air on its own as oxidant $\left(0.154 \mathrm{~m}^{3} / \mathrm{h}\right)$ is sufficient, but presence of $\mathrm{H}_{2} \mathrm{O}_{2}$ gives slight improvement in COD reduction. Any reduction in $\mathrm{COD}$ values due to volatile organic pollutants being stripped from the feed by the bubbling air was accounted for by the use of a blank containing no catalyst. COD reductions due to catalysis were reported throughout this work relative to the COD reductions experienced by the blank.

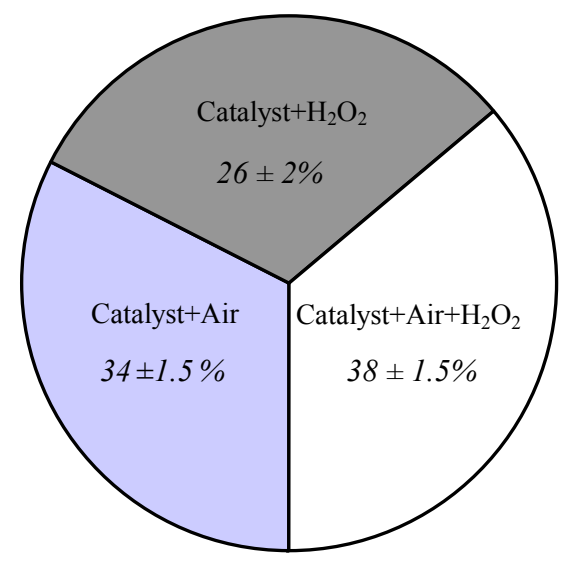

Figure 3: $\quad$ COD reduction of $\mathrm{KODAK} \mathrm{SB}_{1}$ effluent by catalytic oxidation using $\mathrm{Fe}^{3+}$ fibrous catalyst in the presence of air and/or hydrogen peroxide at room temperature.

\subsection{Effect of dilution factor of SB effluent}

KODAK $\mathrm{SB}_{2}$ feed was treated for 1 hour using catalyst, air and hydrogen peroxide. Table 2 shows that for 50 times diluted $\mathrm{SB}_{2}$ effluent (COD around 800 $\mathrm{mg} / \mathrm{L}$ ), using $2.5 \mathrm{~g}$ of catalyst and $50 \mathrm{mg} / \mathrm{L}$ hydrogen peroxide gives a better COD reduction than using $75 \mathrm{mg} / \mathrm{L} \mathrm{H}_{2} \mathrm{O}_{2}$, this is in agreement with the results for 
$\mathrm{SB}_{1}$ effluent. Table 2 also shows that for 15 times diluted $\mathrm{SB}_{2}$ effluent (COD around $2760 \mathrm{mg} / \mathrm{L}$ ), $21 \% \mathrm{COD}$ reduction can be achieved when $5 \mathrm{~g}$ catalyst mesh and $75 \mathrm{mg} / \mathrm{L}$ hydrogen peroxide were used. Therefore the amount of catalyst as well as the concentration of hydrogen peroxide plays a role in COD reduction of KODAK SB effluent, which needs to be studied more extensively.

Table 2: Effect of reaction conditions on the COD reduction of KODAK $\mathrm{SB}_{2}$ effluent at room temperature.

\begin{tabular}{|c|c|c|c|c|c|c|}
\hline $\begin{array}{c}\text { Dilution } \\
\text { factor }\end{array}$ & $\begin{array}{c}\mathrm{H}_{2} \mathrm{O}_{2} \\
(\mathrm{mg} / \mathrm{L})\end{array}$ & $\begin{array}{c}\text { Amount of } \\
\text { catalyst }(\mathrm{g})\end{array}$ & $\begin{array}{c}\mathrm{COD} \\
(\mathrm{mg} / \mathrm{L})\end{array}$ & $\begin{array}{c}\mathrm{COD}_{\text {ref }} \\
(\mathrm{mg} / \mathrm{L})\end{array}$ & $\begin{array}{c}\mathrm{COD}_{\text {cat }} / \\
\mathrm{COD}_{\text {ref }} \\
(\%)\end{array}$ & $\begin{array}{c}\mathrm{COD} \\
\text { reduction } \\
(\%)\end{array}$ \\
\hline 50 & 75 & 2.5 & 642 & 813 & 79 & 21 \\
\hline 50 & 50 & 2.5 & 479 & 761 & 63 & 37 \\
\hline 15 & 75 & 5 & 1570 & 2546 & 62 & 38 \\
\hline
\end{tabular}

\section{Conclusions}

The use of a Novel heterogeneous fibrous catalyst and bubbled air (with no hydrogen peroxide present) resulted in significant COD reduction of silverbearing photo-processing effluent with a maximum value of COD reduction of $56 \%$ at room temperature after 18 hours of treatment. Most of the COD reduction occurred within the first four hours of treatment. Ambient temperature is preferred for the catalytic treatment of the effluent, as an increase in temperature up to $60^{\circ} \mathrm{C}$ leads to less COD reduction which may arise from a change in the redox potential of the active transition metal $\left(\mathrm{Fe}^{3+}\right)$ complex. Range between 10 and $50 \mathrm{mg} / \mathrm{L}$ of $\mathrm{H}_{2} \mathrm{O}_{2}$ was the optimum range in concentration of hydrogen peroxide (when used without air) for the oxidation of $\mathrm{SB}_{1}$ effluent in terms of COD reduction. In this work using hydrogen peroxide as the catalytic oxidant together with air shows little evidence of an improvement in COD reduction over using air alone.

\section{Acknowledgments}

The authors thank KODAK company for financial support and De Montfort University for use of facilities.

\section{References}

[1] Dagon, T. J., The Biological Treatment of Photographic Processing Effluents. Journal of Appl. photogaphic Eng., 4 (2), pp. 62-71, 1978. 
[2] Wang, W.C., Toxicity reduction of photo processing wastewaters. J. Environ. Sci. Health Part A-Environ. Sci. Eng. Toxic Hazard. Subst. Control, 32 (1), pp. 1313-1328, 1992.

[3] Lin, S. M., Yang, H. M., Treatment of photographic effluents by electrochemical method. Environ. Eng. Sci., 14 (4), pp. 201-206, 1997.

[4] Fyson, J. R., Method for treating waste effluent from photographic processing. European Patent Application, EP -200211 19970127, 1997.

[5] Hori, K., Ohara, Y., Treatment of organic wastewaters from photographic processing plants. Japan kokai Tokkyo Koho, Application: JP 90-218059 $19900821,1992$.

[6] Gehin, G. M., Caillault, O. A. G., Treatment of photographic effluents by ultraviolet radiation and hydrogen peroxide for removal of organic compounds. European Patent Application, EP 94-420125 19940419, 1994.

[7] Strauel, P., Process for treating photographic effluents using ultraviolet and hydrogen peroxide. European Patent Application, EP 95-420211 19950724, 1996.

[8] Pavlostathis, S. G., Maeng, S. K., Aerobic biodegradation of a silverbearing photoprocessing wastewater. Environ. Toxicol. Chem., 17 (4), pp. 617-624, 1998.

[9] Hirata, A., Lee, H. S., Tsuneda, S., Takai, T., Treatment of photographic processing wastewater using anaerobic-aerobic biofilm reactor. Water Sci. Technol., 36 (12), pp. 91-99, 1997.

[10] Lunar, L., Sicilia, D., Rubio, S., Perez-Bendito, D. and Nickel, U., Degradation of Photographic Developers by Fenton's Reagent: Condition Optimization and Kinetics for Metol Oxidation. Water Res., 34 (6), pp. 1791-1802, 2000.

[11] Yamazaki, H., Oxidation decomposition of cyanide complexes in wastewaters from photo processing. Japan Kokai Tokkyo Koho, Application: JP 76-149424 19761214, 1978.

[12] Nakajima, R., Ishihara, Y., Kurokawa, R., Furukawa, M., Tanaka, K., Nakajima, K., Treatment of wastewater from photographic development for fixing and developing wastewater systems. Mizu Shori Gijutsu, 30 (8), pp. 457-465, 1989.

[13] Aita, G., Treating of wastewaters from a photographic process. Inquinamento, 26 (5), pp. 61-62, 1984.

[14] Takahashi, A., Myazaki, H., Treatment of wastewater from photographic processing. Japan Kokai Tokkyo Koho, Application: JP 90-60295 $19900312,1991$.

[15] Goto, K., Ishihara, Y., Nakajima, K., Kamata E., Nakashima, R., Treatment of wastewater from photographic developing laboratory. II. Degradation of thiosulfate. Mizu Shori Gijutsu, 28 (3), pp. 167-171, 1987.

[16] Ishtchenko, V.V., Huddersman, K. D., Vitkovskaya, R. F., Part 1. Production of a modified PAN fibrous catalyst and its optimisation towards the decomposition of hydrogen peroxide. Appl. Catal. A-Gen., 242 (1), pp. 123-137, 2003. 
[17] Canelli, E., Mitchell, D.G. and Pause, R.W., An improved determination of Chemical Oxygen Demand in water and wastes by a simplified acid dichromate digestion. Water Res., 10, pp. 351-355, 1976.

[18] Ishtchenko, V.V., Huddersman, K.D., Vitkovskaya, R.F., Tereschenko, L.Y., Romanova, E.P. and Rymynskaya, I.G., A novel catalytic system for the oxidative destruction of toxic organic compounds in industrial wastewaters. J. Chart. Inst. Water E., 17 (1), pp. 13-19, 2003.

[19] Bard, A.J., Parsons, R., Jordan, J., Standard Potentials in Aqueous Solution, Marcel Dekker: New York, p. 408, 1985.

[20] Bossmann, S.H., Oliveros, E., Kantor, M., Niebler, S., Bonfill, A., Shahin, N., Wörner, M. and Braun, A.M., New insights into the mechanisms of the thermal Fenton reactions occurring using different iron (II)complexes. Wat. Sci. Technol., 49 (4), pp. 75-80, 2004.

[21] Talinli, I., Anderson G.K., Interference of Hydrogen Peroxide on the Standard COD Test. Water Res., 26 (1), pp. 107-110, 1992.

[22] Perkowski, J., Kos, L., Treatment of textile dyeing wastewater by hydrogen peroxide and ferrous ions. Fibres Text. East. Eur., 10 (3), pp. 78-81, 2002. 